\title{
The Taylor Rule: A Spurious Regression?*
}

\author{
Pär Österholm*
}

August 2003

\begin{abstract}
This paper investigates the econometric properties of the Taylor (1993) rule applied to U.S., Australian and Swedish data to judge its empirical relevance. Little attention has been paid to the time series properties of the data underlying interest rate rules, nor the estimations themselves, despite the rise in popularity of Taylor-like rules in both empirical and theoretical work. Unit root tests indicate that the variables commonly used in such modelling are likely to be integrated of order one or near integrated. Given that the variables in the Taylor rule are integrated of order one or near integrated processes, cointegration is a necessary condition both for consistent estimation of the parameters of the model and compatibility between the model and the data. Tests find little support for cointegration and, together with an out-of-sample forecast exercise, suggest that we should have serious doubts about the Taylor rule as a reasonable description of how monetary policy is conducted in the countries considered in this study. Parameter estimates from the standard Taylor rule regressions are therefore likely to be inconsistent and caution should be taken before for central bank policy is evaluated using such methods.
\end{abstract}

JEL Classification: E52

Keywords: Monetary policy, Taylor rule, Cointegration

\footnotetext{
* I am grateful to Paul Söderlind for providing U.S. data, David Gruen and Tim Robinson for providing Australian data, Johan Lyhagen for sharing Matlab code and Rolf Larsson, Meredith Beechey and seminar participants at Sveriges Riksbank and Uppsala University for valuable comments. Financial support from Sparbankernas Forskningsstiftelse is gratefully acknowledged.

* Department of Economics, Uppsala University, Box 513, S-751 20 Uppsala, e-mail: par.osterholm@nek.uu.se
} 


\section{Introduction}

During the last decade the interest among macroeconomists in estimating monetary policy reaction functions has increased markedly. The reaction function can, within a macroeconomic model, be used to evaluate the actions and policy of central banks and through these estimations researchers have aimed to gain insight into central bank behaviour. Taylor (1993) made an important contribution to this field with a very simple characterisation of the Federal Reserve's monetary policy. He claimed that expressing the federal funds rate as a linear function of current inflation's deviation from an inflation target and the output gap was not only a good description of previous monetary policy in the U.S., but also a reasonable policy recommendation. Since its introduction, Taylor's rule has become highly popular and versions of it have been used in numerous empirical studies of monetary policy ${ }^{1}$ and frequently in theoretical work ${ }^{2}$.

Whilst the Taylor rule has reached widespread fame and popularity it has lately been questioned. Svensson (2002) argues that the relevance of the Taylor rule for conducting monetary policy should be doubted from a theoretical point of view. Monetary policy conducted by the world's most advanced central banks should be at least as optimising and forward-looking as the behaviour of rational private agents. Svensson therefore finds it strange that a large part of the recent literature on monetary policy represents central bank behaviour by a mechanical instrument rule; the Taylor rule is highly unlikely to be the solution of a central bank's optimisation problem in which the objective is to stabilise inflation and the output gap. If there are important state variables other than inflation and the output gap, it will not be optimal. For a large and not very open economy, the efficiency loss in not responding to other variables than output and inflation may be small, but for a small and open economy Svensson argues that the real exchange rate, terms of trade, foreign output and the foreign interest rate are essential state variables that have to be added. This would increase the number of response coefficients that need to be fixed in the central bank's reaction function.

The theoretical objections regarding the Taylor rule translate into suspicions of misspecification. It is therefore remarkable that previous studies in the area to a large extent have ignored both the time series properties of the included variables and the properties of the

\footnotetext{
${ }^{1}$ See for instance Clarida et al (1998, 2000), Taylor (1999b), Gerlach and Schnabel (2000), Huang et al (2001), Orphanides (2001) and Rudebusch (2002a).

${ }^{2}$ See for instance Levin et al (1999), Leitemo and Söderström (2001) and Rudebusch (2002b).
} 
estimated models, particularly given the strong indications that the variables in the regressions have unit roots, or at least are highly persistent. Phillips $(1986,1988)$ showed that if variables are integrated of order one, I(1), or near integrated - that is have roots close to unity misspecified static regressions using levels are spurious. ${ }^{3}$ Using an estimated Taylor rule to evaluate central bank behaviour or make statements about its preferences over time, the econometric properties of the model should first be scrutinised; these statements should not be based on a model where there are serious reasons to doubt the consistency of the estimated parameters.

The purpose of this paper is to investigate the empirical relevance of the Taylor rule by estimating it for the U.S., Australia and Sweden. Focus is put on the time series properties of the variables and the relevance of the Taylor rule is evaluated using cointegration techniques and an out-of-sample forecast exercise. Given the (near) unit root behaviour of the variables in the Taylor rule found here, the concept of cointegration becomes essential for the model, not only in order to estimate the parameters of the model consistently but to give economic meaning to the relationship. Absence of cointegration means that there is no long-run relationship between the variables in a system and such a finding must lead to the conclusion that the Taylor rule is incompatible with central bank behaviour. Results show that the Taylor rule cannot be rejected as a reasonable description of monetary policy in the U.S. during the 1960 's and 1970's, but that there are serious reasons to doubt the relevance of the rule during later sample periods and in Australia and Sweden.

This paper is organised as follows. Section two presents the Taylor rule and variants thereof in some detail and discusses previous findings in the area. Section three describes data for the countries in this study, performs relevant tests and conducts the out-of-sample forecast exercise. Finally, section four concludes.

\section{The Taylor rule}

Taylor's (1993) original formulation is shown in equation (1),

$$
i_{t}=r^{*}+\pi_{t}+f_{\pi}\left(\pi_{t}-\pi^{*}\right)+f_{y} y_{t}
$$

\footnotetext{
${ }^{3}$ Phillips (1988) considers both processes that have roots smaller than unity (strongly autoregressive) and larger than unity (mildly explosive). In this paper, however, the concept near integration will always refer to processes with roots smaller than unity.
} 
where $i_{t}$ is the central bank policy rate, $r^{*}$ is the equilibrium real interest rate, $\pi_{t}$ the twelve month inflation rate, $\pi^{*}$ the inflation target of the central bank and $y_{t}$ the output gap. Taylor found that a rule, with the parameters set arbitrarily to $r^{*}=2, \pi^{*}=2, f_{\pi}=0.5$ and $f_{y}=0.5$ tracked the actual federal funds rate fairly well between 1987 and 1992. Rewriting equation (1) slightly and dropping restrictions on coefficients, this can be expressed as

$i_{t}=\alpha+\beta_{\pi}\left(\pi_{t}-\pi^{*}\right)+\beta_{y} y_{t}$

where $\alpha=r^{*}+\pi^{*}$ and $\beta_{\pi}=1+f_{\pi}$. The policy rate of the central bank - which in the original paper is meant to be the federal funds rate - is decomposed into response to deviations of current inflation from its target rate, response to the output gap from its target rate zero and a constant containing the equilibrium real interest rate and the inflation target.

Many variants of this basic rule has been employed in both theoretical and empirical work. One simple alternative to the Taylor rule of equation (2) is to use forecasts of the variables in the reaction function as in equation (3) below, as in for instance Orphanides (2001).

$i_{t}=\alpha+\beta_{\pi}\left(E_{t}\left[\pi_{t+k}\right]-\pi^{*}\right)+\beta_{y} E_{t}\left[y_{t+m}\right]$

This specification is preferred by some researchers because it attempts to capture the explicit forward looking behaviour of some central banks. Several countries have during the last decade reformed their monetary policy to practice what best could be described as inflation forecast targeting, namely Australia, the Czech republic, New Zealand, Sweden and the U.K. among others. Explicit inflation forecast targeting by the central bank is, however, not a necessary condition for forward looking behaviour; it is also a reasonable assumption for the behaviour of other central banks, such as the Federal Reserve. From a theoretical point of view, the policies of inflation forecast targeting countries should probably be interpreted as specific targeting rules and not instrument rules ${ }^{4}$, but does not exclude the Taylor rule as a reasonable approximation.

\footnotetext{
${ }^{4}$ Targeting and instrument rules are here defined as formally proposed by Svensson (1999), where a specific targeting rule means a commitment to set the instrument rate so as to achieve a specific target criterion for the target variables and an instrument rule expresses the instrument as a prescribed function of variables in the current information set. This definition can be contrasted with McCallum and Nelson's (1999) definition of targeting.
} 
A common modification of Taylor's rule, justified by the view held by some economists that central banks tend to smooth adjustments in the interest rate, is the addition of a lagged interest rate term as in equation (4).

$i_{t}=(1-\rho)\left\{\alpha+\beta_{\pi}\left(E_{t}\left[\pi_{t+k}\right]-\pi^{*}\right)+\beta_{y} E_{t}\left[y_{t+m}\right]\right\}+\rho i_{t-1}$

where $\rho \in[0,1)$. Levin et al (1999) for instance argue that this behaviour could be an optimal response for a central bank and such interest rate smoothing has been employed in empirical work by Clarida et al (1998, 2000), Gerlach and Schnabel (2000) and Doménech et al (2002). In general, $\hat{\rho}$ in the estimated equations has been highly significant, which has been interpreted as evidence for the hypothesis that central banks adjust the interest rate gradually towards its target rate. The coefficient $\rho$ decides the speed of this adjustment and is often fairly high, which implies a slow adjustment process. However, the conclusion of a significant estimate of $\rho$ as a sign of interest rate smoothing has been questioned recently by Rudebusch (2002a) and Söderlind et al (2003), both of whom argue that a Taylor rule with interest rate smoothing generates much more interest rate predictability than can be found in the data.

Even though reasons to doubt the appropriateness of the Taylor rule have been presented, the rule has also been shown to have a number of appealing features. Leitemo and Söderström (2001) find the Taylor rule robust when there is uncertainty about the exchange rate model using a New-Keynesian open economy model and Nyberg (2002) gives further support arguing that it is a reasonable rule even in an open economy when there is parameter uncertainty. It appears that the Taylor rule is robust in the sense of performing well in a number of different macro models, a conclusion also supported by Levin et al (1999), Taylor (1999a) and Rudebusch (2002b) for instance.

From an empirical point of view, our primary interest is whether the estimated parameters from a regression are meaningful to interpret. For this to be the case, the rule should either have been used by central banks or at least be a close enough approximation to central bank behaviour. The former is unlikely to be the case; no central bank has so far made a statement that it has committed to a simple instrument rule like the Taylor rule and even Taylor (1993, p. 213) states that "... such rules cannot and should not be mechanically followed by policymakers". However, despite this claim, Taylor still argued that the rule was a good policy 
recommendation and the Taylor rule has been advocated by decision makers within central banks, such as Federal Reserve Board Governor Yellen (Federal Reserve Board, 1995). It is also possible that, even if inflation forecast targeting is the official policy of a central bank, it could actually be following a Taylor rule in disguise. Misrepresentation of central bank policy has been established by for instance Bernanke and Mihov (1997) who found evidence that Bundesbank was actually targeting inflation when it claimed to target money growth. However, it is probably more likely that the latter argument - of the Taylor rule being an approximation to central bank behaviour - is the most reasonable.

\subsection{Empirical tests of the Taylor rule}

To answer the question whether the Taylor rule is a good representation of central bank behaviour, it must be tested against data and a number of studies have endeavoured to do this for different time periods, countries and specifications. In Taylor's (1993) initial work, no formal econometric study was performed and the simple rule in equation (1) was found to visually track the federal funds rate fairly well between 1987 and 1992. Taylor (1999b) estimated a modified version of equation (2), shown in (5), for the U.S. over several different sample periods using OLS. ${ }^{5}$

$i_{t}=\delta+\beta_{\pi} \pi_{t}+\beta_{y} y_{t}+\varepsilon_{t}$

where $\delta=r^{*}-\left(\beta_{\pi}-1\right) \pi^{*}$. Taylor concluded that the size of the response coefficients has increased over time between the international gold standard era and the Bretton Woods and post-Bretton Woods era. Using the same specification and estimation method, Hetzel (2000) compares the 1965-1979, 1979-1987 and 1987-1999 periods for the U.S.. The response coefficients are found to increase over time, but Hetzel questions whether these can be given structural interpretations. ${ }^{6}$

Many authors have followed in Taylor's path, estimating variants the rule. Orphanides (2001) estimates the Taylor rule for the U.S. during 1987-1992 using LS and IV on the specifications in equation (2), (3) and (4). Applying them to both ex post and real time data, he makes two major points: first and most important, when real time data are used, the rule seems to give a

\footnotetext{
${ }^{5}$ Similar modifications are made to equations (3) and (4) when they are being estimated.

${ }^{6}$ Whether it is reasonable to interpret Taylor rule regressions as reaction functions for monetary policy has also been questioned by Minford et al (2002), where it is shown in a theoretical framework that a relation between interest rates, inflation and the output gap could be an outcome from quite different rules.
} 
much less accurate description of policy than when ex post data are used. Second, forward looking versions of the Taylor rule seem to describe policy better than contemporaneous specifications, particularly so using real time data. Using OLS and IV on New Zealand data from 1989 to 1998, Huang et al (2001) estimate the specifications in equation (2), (3) and (4), concluding that the forward looking version of the Taylor rule performs better than a contemporary variable specification, although the differences are minor.

In Clarida et al (1998) reaction functions with a lagged interest rate included are estimated with GMM for Germany, Japan, the U.S., the U.K., France and Italy using data between 1979 and 1992. Their results support the idea that central banks are forward looking, but also apply a high degree of interest rate smoothing. Clarida et al (2000) consider two sub-samples, 19601979 and 1979-1996 for the U.S. and using the same specification, claim that there are substantial differences in response coefficients during the different periods. Doménech et al (2002) challenge these results by finding results supporting the view of an activist monetary policy in the U.S. in the seventies resembling that of the eighties and nineties. Results for the EMU area are also interpreted as support for forward looking central banks using interest rate smoothing. More support for the Taylor rule in the EMU area was found by Gerlach and Schnabel (2000) who estimated equations (2), (4) and variants thereof on data from 1990 to 1998 with GMM, concluding that monetary policy in the EMU area had largely been consistent with the Taylor rule.

Unlike much of the literature, which largely has been supportive of Taylor rules, the above mentioned papers by Rudebusch (2002a) and Söderlind et al (2003) provide empirical arguments questioning the Taylor rule. It is shown that a Taylor rule with interest rate smoothing predicts much more interest rate predictability than can be found in the data and after applying the rule to U.S. data from 1988 to 2000 it is concluded that there are inconsistencies between the rule and the data. While Rudebusch does not abandon the Taylor rule completely - he argues that the significant parameter found on lagged interest rates reflects serially correlated shocks to the economy - Söderlind et al claim that the Taylor rule has fundamental problems. 
In none of the above mentioned studies have the time series properties of the variables in the Taylor rule been properly addressed and with a few exceptions they are completely ignored. ${ }^{7}$ This is especially distressing since there is evidence that the variables in the Taylor rule contain unit roots for some countries and sub-samples. ${ }^{8}$ If variables are found to be integrated of order one or near integrated, but not cointegrated, a static regression in levels like equation (5) above is spurious. It is well known that when a regression is spurious, the estimated parameter vector is inconsistent and $t$-and $F$-statistics diverge. ${ }^{9}$ Among the studies using static regressions like (5), Taylor (1999b) report nothing except parameter estimates, $t$-values of the estimated coefficients and the multiple coefficient of determination $\left(R^{2}\right)$ and Hetzel (2000) reports the same plus the standard error of regression and the Durbin-Watson statistic. The fact that the $R^{2}$ is by far larger than the Durbin-Watson statistic in Hetzel's regressions - which according to Granger and Newbold (1974) is a sign that the regression is likely to be spurious - passed without further notice. Such modest scrutiny of the statistical properties of the models is a serious shortcoming. Since interpretation of estimated coefficients based on spurious regressions is highly dubious, the properties of the estimated model should be established before any inference is made about central bank behaviour.

Another issue regarding the order of integration of the variables is the possible simultaneity in equation (5). Unless inflation and the output gap in time $t$ are predetermined, OLS regression will not yield consistent estimates and IV techniques should be used when all variables are stationary. ${ }^{10}$ However, if the variables are I(1) or near integrated and cointegrated, OLS regression of equation (5) will yield not only consistent, but superconsistent estimates regardless of whether there is simultaneity or not. This is an obvious advantage when it comes to estimation if the variables are in fact I(1) and the Taylor rule is relevant - that is, we have cointegration. Having stressed the importance of the time series properties of the variables and of a good specification of the econometric model, we now turn to the empirical study in this paper.

\footnotetext{
${ }^{7}$ Clarida et al (1998) perform some unit root tests, but find mixed results regarding the order of integration for the included variables. They conclude by assuming that all variables are stationary after all and that the mixed results are due to low power of the unit root test. Unit root tests and cointegration tests are also performed - but unfortunately not reported in detail - by Huang et al (2001) in order to find statistical support for estimation of the Taylor rule. Apart from interest rate, inflation and the output gap, the real exchange rate was also included in a system and all variables were found to be I(1). The Johansen trace test and maximum eigenvalue test were then applied to the data and both supported one cointegrating vector in the system.

${ }^{8}$ See for instance Goodfriend (1991), Mishkin (1992), Crowder and Hoffman (1996) and Culver and Papell (1997).

${ }^{9}$ See for instance Phillips $(1986,1988)$.

${ }^{10}$ Modelling inflation and the output gap as forward looking is one way of not making these variables predetermined. Svensson (2002), however argues that "in any realistic model, current inflation and the output gap are predetermined".
} 


\section{Empirical study}

There are a number of possible specifications of the Taylor rule, but in this section the focus will be on equation (5) with contemporary variables. Not only is this version closest to Taylor's original formulation, but it has also been used frequently in empirical work and is furthermore a special case of more elaborate models. Investigating the properties of this rule will, hence, serve as a useful benchmark. U.S., Australian and Swedish data will here be used to test the Taylor rule. This choice is based on the fact that the U.S. was the country for which the Taylor rule was initially intended and the focus of most research, whilst Australia and Sweden are of interest since they can tell us something about the appropriateness of the Taylor rule for countries that explicitly target inflation forecasts.

Quarterly data are available for all three countries, but for different time periods. For the U.S., the full sample is 1960:1-1999:4, for Australia it is 1993:1-2001:4 and for Sweden 1992:42002:2. The U.S. sample will, as in a number of previous studies, be divided into sub-samples according to the chairman in the Federal Reserve. ${ }^{11}$ For Australia and Sweden, the samples correspond to the periods of inflation forecast targeting in these countries. Data on US variables were supplied by Bureau of Economic Analysis (CPI inflation), Federal Reserve Bank of St Louis (GDP and federal funds rate) and Congressional Budget Office (potential $G D P$ ). Australian data were supplied by Reserve Bank of Australia (output gap) and Ecowin (cash target rate and CPI inflation) and data on Swedish variables were supplied by Central Bank of Sweden (output gap) and Ecowin (repo rate and CPI inflation).

\subsection{Time series properties and cointegration tests}

The initial step in the empirical analysis is to investigate the time series properties of the included variables with focus on the persistence of the variables in the Taylor rule. For this purpose the Augmented Dickey-Fuller (Said and Dickey, 1984) and KPSS (Kwiatkowski et al, 1992) tests will be used. The Augmented Dickey-Fuller (ADF) test has been shown to have good size and power properties in a number of studies and is therefore preferred to other tests with unit root under the null hypothesis. ${ }^{12}$ The lag length used in the test is determined using the Akaike (1974) information criterion. To complement the ADF test, the KPSS test, which

\footnotetext{
${ }^{11}$ See for instance Taylor (1999b), Clarida et al (2000) and Doménech et al (2002).

${ }^{12}$ See for instance Schwert (1989) and Pantula (1991).
} 
has stationarity under its null, is used. The KPSS test is here performed with a Bartlett kernel where the bandwidth parameter is selected using the Newey and West (1994) automatic bandwidth parameter method.

The results, given as test statistics, for the unit root tests for all countries and different subsamples are shown in Tables 1 and 2. Looking at the U.S., the ADF and KPSS tests agree that the order of integration of the federal funds rate is one for the period 1960:1-1979:2, whereas they reach conflicting conclusions for the other three samples. Regarding inflation the tests are even more supportive of the unit root hypothesis; they both find that inflation is I(1) for the 1960:1-1979:2 and 1987:4-1999:4 samples and reach conflicting results otherwise. Turning to the output gap, both tests find it to be stationary for the full sample. However, the results from the different sub-samples conflict - the ADF test cannot reject the null of a unit root and the KPSS test is unable to reject its null of stationarity.

Table 1. Results from unit root tests on individual series for the U.S.

\begin{tabular}{|c|c|c|c|c|c|c|c|c|}
\hline & \multicolumn{2}{|c|}{$\begin{array}{c}\text { U.S. } \\
\text { 1960:1-1999:4 }\end{array}$} & \multicolumn{2}{|c|}{$\begin{array}{c}\text { U.S. } \\
\text { 1960:1-1979:2 }\end{array}$} & \multicolumn{2}{|c|}{$\begin{array}{c}\text { U.S. } \\
\text { 1979:3-1999:4 }\end{array}$} & \multicolumn{2}{|c|}{$\begin{array}{c}\text { U.S. } \\
\text { 1987:4-1999:4 }\end{array}$} \\
\hline & ADF & KPSS & $\mathrm{ADF}$ & KPSS & ADF & KPSS & ADF & KPSS \\
\hline$i_{t}$ & -2.352 & 0.325 & -2.424 & $0.759^{* \star}$ & $-3.200^{*}$ & $0.933^{\star \star}$ & -2.025 & 0.300 \\
\hline$\Delta i_{t}$ & $-5.472^{* *}$ & 0.070 & $-3.649^{\star *}$ & 0.064 & $-8.564^{\star \star}$ & 0.061 & $-3.151^{\star \star}$ & 0.102 \\
\hline$\pi_{t}$ & -1.798 & 0.277 & -0.977 & $0.996^{* *}$ & $-4.674^{* *}$ & $0.700^{*}$ & -1.540 & $0.636^{*}$ \\
\hline$\Delta \pi_{t}$ & $-5.163^{* *}$ & 0.088 & $-3.850^{* *}$ & 0.059 & $-3.304^{* *}$ & 0.206 & $-2.765^{\star \star}$ & 0.118 \\
\hline$y_{t}$ & $-3.132^{*}$ & 0.301 & -2.638 & 0.199 & -1.885 & 0.418 & -0.452 & 0.276 \\
\hline$\Delta y_{t}$ & $-6.561^{* *}$ & 0.063 & $-6.855^{* *}$ & 0.060 & $-3.963^{* *}$ & 0.174 & $-3.054^{* *}$ & 0.357 \\
\hline
\end{tabular}

The results for the Australian data support that the output gap should be modelled as I(1), since both unit root tests find this conclusion. Regarding inflation and the cash target rate the tests disagree; the ADF test cannot reject the null that the series are I(1) and the KPSS test is unable to reject the null of stationarity. Looking at Sweden, there is even more support that the series are I(1); the repo rate and the output gap are found to be I(1) by both tests and there are conflicting results for inflation. 
Table 2. Results from unit root tests on individual series for Australia and Sweden.

\begin{tabular}{|c|c|c|c|c|}
\hline & \multicolumn{2}{|c|}{$\begin{array}{c}\text { Australia } \\
\text { 1993:1-2001:4 }\end{array}$} & \multicolumn{2}{|c|}{$\begin{array}{c}\text { Sweden } \\
\text { 1992:4-2002:4 }\end{array}$} \\
\hline & $\mathrm{ADF}$ & KPSS & ADF & KPSS \\
\hline$i_{t}$ & -1.908 & 0.193 & -2.052 & $0.647^{*}$ \\
\hline$\Delta i_{t}$ & $-3.625^{* \star}$ & 0.131 & $-3.069^{* \star}$ & 0.245 \\
\hline$\pi_{t}$ & -2.196 & 0.144 & -2.937 & 0.319 \\
\hline$\Delta \pi_{t}$ & $-3.849^{* *}$ & 0.070 & $-2.395^{*}$ & 0.069 \\
\hline$y_{t}$ & -1.585 & $0.610^{*}$ & -0.923 & $0.555^{*}$ \\
\hline$\Delta y_{t}$ & $-5.627^{\star *}$ & 0.178 & $-3.021^{\star \star}$ & 0.195 \\
\hline
\end{tabular}

A general conclusion drawn from the above results is that it is hard to find conclusive evidence of stationarity among the investigated variables. Worth noting is that the results of the unit root tests for inflation for Australia and Sweden are less supportive of stationarity than might be expected. Since both countries aim to keep inflation constant at their target rates of 2.5 and 2 percent respectively we would expect inflation to be stationary processes with means equal to the target rates in these countries. The only variable found unanimously stationary by the two unit root tests is the output gap in the U.S. for the full sample period. Hence, when it comes to econometric modelling of the variables in the Taylor rule, it seems appropriate to describe them as $\mathrm{I}(1)$ or near integrated.

Considering the above results, there is an obvious risk of running a spurious regression using the formulation in equation (5) to estimate the Taylor rule on these data. ${ }^{13}$ Close inspection of the properties of the estimated models are, hence, required and testing for cointegration will be an important part of this. Testing for cointegration can be done in numerous ways. In this paper four different tests will be considered: the Augmented Engle-Granger (Engle and Granger, 1987 ) test, the KPSS test applied in the fashion proposed by Shin (1994), the Johansen (1988) maximum eigenvalue test and the Johansen (1991) trace test. ${ }^{14}$ Lag length in the Augmented Engle-Granger (AEG) test and the bandwidth parameter in the KPSS test are chosen using the same procedures as in the ordinary unit root tests, that is by the Akaike information criterion and the Newey-West method. Since OLS regression of equation (5) also is the first step of the

\footnotetext{
${ }^{13}$ Spurious regressions are present for near-integrated variables also in small samples as shown by DeBoef and Granato (1997).

${ }^{14}$ A brief description of the different cointegration tests is given in Appendix 1 and properties of the AEG and Johansen tests when applied to processes with roots less than unity are discussed in Appendix 2.
} 
AEG and KPSS tests, this will be our starting point for our analysis of the Taylor rule. ${ }^{15}$ The top panel of Table 3 presents results from OLS estimation of equation (5) on U.S. data for the four different periods.

Table 3. Estimated Taylor rules for the U.S.

\begin{tabular}{|c|c|c|c|c|}
\hline & $\begin{array}{c}\text { U.S. } \\
\text { 1960:1-1999:4 }\end{array}$ & $\begin{array}{c}\text { US } \\
\text { 1960:1-1979:2 }\end{array}$ & $\begin{array}{c}\text { US } \\
1979: 3-1999: 4 \\
\end{array}$ & $\begin{array}{c}\text { US } \\
\text { 1987:4-1999:4 }\end{array}$ \\
\hline \multicolumn{5}{|l|}{ OLS } \\
\hline $\begin{array}{l}\hat{\delta} \\
\hat{\beta}_{\pi}\end{array}$ & $\begin{array}{c}3.141^{* \star} \\
(5.274) \\
0.787^{\star \star} \\
(7.071)\end{array}$ & $\begin{array}{c}1.288^{\star *} \\
(6.124) \\
0.742^{\star *} \\
(15.314)\end{array}$ & $\begin{array}{c}3.803^{* *} \\
(4.845) \\
0.881^{* *} \\
(5.588)\end{array}$ & $\begin{array}{c}1.010 \\
(1.738) \\
1.182^{\star \star} \\
(9.409)\end{array}$ \\
\hline$\hat{\beta}_{y}$ & $\begin{array}{c}-0.056 \\
(-0.395)\end{array}$ & $\begin{array}{c}0.334^{\star *} \\
(5.028)\end{array}$ & $\begin{array}{r}-0.1661 \\
(-1.026)\end{array}$ & $\begin{array}{c}0.636^{* *} \\
(4.847)\end{array}$ \\
\hline$R^{2}$ & 0.578 & 0.857 & 0.655 & 0.802 \\
\hline DW & $0.228^{*}$ & $0.693^{*}$ & $0.330^{*}$ & $0.454^{*}$ \\
\hline $\mathrm{F}$ & $107.550^{* *}$ & $224.108^{* *}$ & $74.986^{* *}$ & $92.965^{* *}$ \\
\hline$\hat{\sigma}_{\varepsilon}$ & 2.107 & 0.930 & 2.099 & 0.819 \\
\hline $\begin{array}{l}\text { Chow } \\
\text { IB }\end{array}$ & $\begin{array}{c}36.864^{* *} \\
{[1980: 1]} \\
1.631\end{array}$ & $\begin{array}{c}10.429^{* *} \\
{[1969: 4]} \\
4.056\end{array}$ & $\begin{array}{c}27.731^{* *} \\
{[1989: 4]} \\
0.508\end{array}$ & $\begin{array}{c}2.717 \\
{[1993: 4]} \\
1.563\end{array}$ \\
\hline ARCH-LM & $96.115^{* *}$ & $10.838^{*}$ & $40.377^{* *}$ & $11.776^{*}$ \\
\hline AEG & -2.129 & $-3.965^{*}$ & -1.989 & -3.762 \\
\hline KPSS & $0.298^{*}$ & 0.101 & $0.429^{\star *}$ & 0.076 \\
\hline \multicolumn{5}{|l|}{ Johansen } \\
\hline $\begin{array}{l}\hat{\delta} \\
\hat{\beta}_{\pi}\end{array}$ & $\begin{array}{c}-13.862^{* *} \\
(-3.183) \\
3.703^{* *} \\
(5.070)\end{array}$ & $\begin{array}{c}2.161^{* *} \\
(7.911) \\
0.617^{* *} \\
(14.574)\end{array}$ & $\begin{array}{c}-5.251^{* *} \\
(-2.758) \\
3.050^{\star *} \\
(8.963)\end{array}$ & $\begin{array}{c}-1.804 \\
(1.795) \\
1.935^{* *} \\
(7.023)\end{array}$ \\
\hline$\hat{\beta}_{y}$ & $\begin{array}{l}1.905^{* \star} \\
(2.159)\end{array}$ & $\begin{array}{l}0.164^{* *} \\
(3.097)\end{array}$ & $\begin{array}{c}0.574 \\
(1.308)\end{array}$ & $\begin{array}{l}0.751^{* *} \\
(3.957)\end{array}$ \\
\hline JB & $460.613^{* \star}$ & 11.181 & $15.403^{*}$ & 4.667 \\
\hline$J_{\text {trace }}^{R A}$ & 33.466 & $43.183^{* *}$ & $39.817^{*}$ & 20.317 \\
\hline$J_{\max }^{R A}$ & 17.304 & $32.922^{* *}$ & $22.012^{*}$ & 11.532 \\
\hline
\end{tabular}

Standard errors Newey-West corrected in OLS estimations; $t$-values in parentheses().

$D W$ is the test statistic from the Durbin-Watson test for first order autocorrelation.

$F$ is the test statistic from the standard F-test

$\hat{\sigma}_{\varepsilon}$ is the standard error of the regression

Chow is the test statistic from the F-test of structural change; breakpoints in parentheses[].

$J B$ is the test statistic from the Jarque-Bera test for normality.

ARCH-LM is the test statistic from the LM test for autoregressive conditional heteroscedasticity.

$J_{\text {trace }}^{R A}$ is the test statistic from the Johansen's trace test adjusted by the Reinsel and Ahn correction.

$J_{\max }^{R A}$ is the test statistic from Johansen's maxiumum eigenvalue test adjusted by the Reinsel and Ahn correction.

${ }^{* *}$ significant at the $1 \%$ level

${ }^{*}$ significant at the $5 \%$ level

\footnotetext{
${ }^{15}$ Note that the estimation of equation (5) is relevant when testing for cointegration - and provides a superconsistent estimate of the cointegrating vector - even if the true data generating process is of interest rate smoothing type, such as $i_{t}=(1-\rho)\left(\delta+\beta_{\pi} \pi_{t}+\beta_{y} y_{t}\right)+\rho i_{t-1}+\varepsilon_{t}$.
} 
All four sample periods yield estimated rules where the point estimate of the response coefficient on inflation is between 0.7 and 1.2 and judging by the $t$-statistics ${ }^{16}$ it is significantly different from zero in all cases. However, for the full sample and the 1960:1 to 1979:2 subsample the coefficient is at the same time significantly less than one, which violates the stability condition for the Taylor rule. The coefficient appears to increase over time, as found by for instance Taylor (1999b) and Clarida et al (2000). The response coefficient on the output gap is smaller and only significantly different from zero in two of the sub-samples. Judging by the $R^{2}$ from the regressions, the fit also seems fairly good but the model appears to have a number of problems; the Durbin-Watson test shows that the residuals have significant first order autocorrelation and they are also found to be heteroscedastic. According to the Chow test, the model also appears to have problem with parameter instability in three of the subsamples. Comparing the $R^{2}$ to the Durbin-Watson statistic, we find that the $R^{2}$ in all cases is larger which, as previously mentioned, could be a sign of the regressions being spurious.

Testing for cointegration using the AEG and KPSS test, this suspicion is partly supported; for the full sample period and the 1979:3 to 1999:4 sub-sample, the two tests both find that there is no cointegration. For the 1987:4 to 1999:4 sub-sample, the AEG test is unable to reject the null of no cointegration whereas the KPSS test is unable to reject the null of cointegration. Finally, for the sub-sample 1960:1 to 1979:2 the two tests both reach the conclusion of cointegration.

The results from OLS estimation of equation (5) on Australian and Swedish data are found in the top panel of Table 4. For Australia, the response coefficient on both variables are small and even though $\hat{\beta}_{\pi}$ is significantly different from zero on the five percent level, it violates the stability condition by being significantly less than one. The $R^{2}$ is not particularly high, but very close to the value of the significant Durbin-Watson statistic. Considering the question of cointegration, the two tests are both unable to reject their null hypothesis, leaving us with no strong support for either claim. On the Swedish data the response coefficients are also low, especially the estimate of $\hat{\beta}_{y}$ which is significantly negative, contrary to theory. The parameter instability found in all but one of the other samples is present also for Sweden and, once again, the $R^{2}$ is higher than the Durbin-Watson statistic. There is obviously reason to believe that the regression is misspecified and, hence, that the regression is spurious. Looking at the results

\footnotetext{
${ }^{16}$ Inference based on $t$-statistics from the regressions should be interpreted with some caution even when the standard errors have been Newey-West corrected. The reason for this is twofold: when there is no cointegration, the $t$-statistics diverge since the residuals behave like a unit root process; when there on the other hand is cointegration, the distribution of the $t$-statistics are only asymptotically standard normal when the regressors are strongly exogenous for the estimation of the cointegrating vector.
} 
from the AEG and KPSS tests, this suspicion is confirmed; they both conclude that there is no cointegration.

Table 4. Estimated Taylor rules for Australia and Sweden.

\begin{tabular}{|c|c|c|}
\hline & $\begin{array}{c}\text { Australia } \\
\text { 1993:1-2001:4 }\end{array}$ & $\begin{array}{c}\text { Sweden } \\
\text { 1992:4-2002:4 }\end{array}$ \\
\hline \multicolumn{3}{|l|}{ OLS } \\
\hline $\begin{array}{l}\hat{\delta} \\
\hat{\beta}_{\pi}\end{array}$ & $\begin{array}{c}4.710^{* *} \\
(20.256) \\
0.297^{\star} \\
(2.330)\end{array}$ & $\begin{array}{c}4.277^{\star *} \\
(13.021) \\
0.569^{*} \\
(2.133)\end{array}$ \\
\hline$\hat{\beta}_{y}$ & $\begin{array}{c}-0.131 \\
(-1.080)\end{array}$ & $\begin{array}{l}-0.578^{\star *} \\
(-3.082)\end{array}$ \\
\hline$R^{2}$ & 0.312 & 0.562 \\
\hline DW & $0.325^{*}$ & $0.312^{*}$ \\
\hline $\mathrm{F}$ & $7.498^{* *}$ & $23.107^{* *}$ \\
\hline$\hat{\sigma}_{\varepsilon}$ & 0.907 & 1.548 \\
\hline Chow & $\begin{array}{c}19.876^{* *} \\
{[1997: 2]} \\
0.895\end{array}$ & $\begin{array}{c}17.561^{* *} \\
{[1997: 3]} \\
6.687^{\star}\end{array}$ \\
\hline $\begin{array}{l}\text { JB } \\
\text { ARCH-LM }\end{array}$ & $\begin{array}{l}0.895 \\
8.100\end{array}$ & $\begin{array}{r}6.687^{\star} \\
29.140^{\star *}\end{array}$ \\
\hline AEG & -1.369 & -2.446 \\
\hline KPSS & 0.217 & $0.342^{*}$ \\
\hline \multicolumn{3}{|l|}{ Johansen } \\
\hline $\begin{array}{l}\hat{\delta} \\
\hat{\beta}_{\pi}\end{array}$ & $\begin{array}{c}8.967^{* *} \\
(4.336) \\
-1.181^{*} \\
(1.970)\end{array}$ & $\begin{array}{c}6.896^{\star *} \\
(3.678) \\
-0.046 \\
(-0.051)\end{array}$ \\
\hline$\hat{\beta}_{y}$ & $\begin{array}{l}-0.667 \\
(-1.245)\end{array}$ & $\begin{array}{l}-4.131^{* *} \\
(-4.899)\end{array}$ \\
\hline JB & $30.388^{* *}$ & $65.757^{\star *}$ \\
\hline$J_{\text {trace }}^{R A}$ & 13.923 & $35.516^{*}$ \\
\hline$J_{\max }^{R A}$ & 7.504 & 19.374 \\
\hline
\end{tabular}

Standard errors Newey-West corrected in OLS estimations; $t$-values in parentheses().

$D W$ is the test statistic from the Durbin-Watson test for first order autocorrelation.

$F$ is the test statistic from the standard F-test

$\hat{\sigma}_{\varepsilon}$ is the standard error of the regression

Chow is the test statistic from the F-test of structural change; breakpoints in parentheses[].

$J B$ is the test statistic from the Jarque-Bera test for normality.

ARCH-LM is the test statistic from the LM test for autoregressive conditional heteroscedasticity.

$J_{\text {trace }}^{R A}$ is the test statistic from the Johansen's trace test adjusted by the Reinsel and Ahn correction.

$J_{\max }^{R A}$ is the test statistic from Johansen's maxiumum eigenvalue test adjusted by the Reinsel and Ahn correction.

*** significant at the $1 \%$ level

* significant at the $5 \%$ level

So far the results from the AEG and KPSS tests have been mixed for the U.S. and Australia. To see whether more light can be shed on the matter, we next turn to the Johansen tests. Generally, asymptotic critical values are used when determining the cointegrating rank of a system.

However, Cheung and Lai (1993) showed that these values often are poor approximations in 
finite samples - especially when the dimension of the VAR is large and the lag length is high finding size distortions in a Monte Carlo study. Therefore the finite sample correction of Reinsel and Ahn (1988) will be used in this paper, which means that the test statistic is multiplied by the factor $(T-n p) / T$ and then compared to the asymptotic critical value. $T$ corresponds to the sample size, $n$ to the dimension of the VAR and $p$ is the number of lags in the VAR. Lag length in the vector error correction model on which the tests are based is determined by applying the Akaike information criterion to the VAR in levels.

The lower panel of Table 3 presents the results from the Johansen tests for the U.S.. The estimate of the cointegrating vector is also presented, regardless of whether the null hypothesis of no cointegration was rejected or not. Neither the maximum eigenvalue test nor the trace test find any support for cointegration for the full sample, supporting the conclusion of the AEG and KPSS tests. For the two sub-samples 1960:1 to 1979:2 and 1979:3 to 1999:4 both tests find support of one cointegrating vector. The result for the first sub-sample supports the earlier conclusion of cointegration found by the residual based tests and we can also notice fairly similar point estimates of the cointegrating vector. The result for the 1979:3 to 1999:4 sample on the other hand contrasts the previous findings where no cointegration was found. The contrasting findings also holds for the estimated cointegrating vectors, where the Johansen method yields a highly significant negative intercept and a response coefficient for inflation that is very high. Finally, for the 1987:4 to 1999:4 sub-sample neither of the two Johansen tests can find support of cointegration, in line with the finding of the AEG test earlier.

Looking at the results for Australia in the lower panel of Table 4, no support can be found for cointegration in the Australian data using either of the tests. This finding seems reasonable when looking at the estimate of the cointegrating vector, where $\hat{\beta}_{\pi}$ is found significantly negative. For Sweden the tests disagree - the trace test supports one cointegrating vector, whereas the maximum eigenvalue test finds no cointegration. However, the estimate of the cointegrating vector is not very supportive of the Taylor rule as a reasonable description of the Swedish economy; the estimate of $\hat{\beta}_{\pi}$ is not significantly different from zero and $\hat{\beta}_{y}$ is found to be negative. The rejection of residual multivariate normality found by the Jarque-Bera test in two of the American sub-samples as well as for Australia and Sweden is worth a comment since the Johansen tests rests on a normality assumption. Cheung and Lai (1993) found that the maximum eigenvalue test is robust to excess kurtosis but less so to the presence of large skewness, whereas the trace test is robust to both skewness and kurtosis. Therefore, the 
deviations from normality found in these systems - which is found to largely be an outcome of excess kurtosis - need not influence the behaviour of neither the trace test nor the maximum eigenvalue test much.

Summing up the results on the cointegration tests, the evidence of cointegration between the variables in the Taylor rule is not overwhelming. The exception is the 1960:1 to 1979:2 subsample for the U.S., where all four tests conclude that there is cointegration. It could be claimed that absence of cointegration in the long sample could be due to structural breaks, since there is very likely to have been at least some differences in regimes in the U.S. between 1960 and 1999. This argument - which is supported by the significant Chow test - is hard to deny and is a reason to question the relevance of a very simple specification over long samples, which can be found in for instance Taylor (1999b). It is, however, also hard to find evidence that there is cointegration in some of the sub-samples. Nor can much support be found when looking at the inflation forecast targeting countries Australia and Sweden for whom the Taylor rule could be prescribed. Taken together, this points to the possibility that the problem might be a more fundamental misspecification of the Taylor rule. The likely inconsistency of parameter estimates implied by such misspecification should make us question the appropriateness of the Taylor rule regressions for policy evaluation.

\subsection{Forecasts}

The above regressions and tests tell us something about the empirical performance of the Taylor rule. So far, some support for the Taylor rule has been found in the data. However, the evidence in favour of the rule is not very convincing and that the rule suffers from some kind of misspecification is a reasonable conclusion. Misspecification must naturally be considered a shortcoming of any model, but it need not necessarily disqualify it from being useful in forecasting purpose. The probability of the model being useful though, is of course drastically reduced if it does not fulfil the assumptions underlying the estimation; as Granger and Newbold (1986, p. 210) argue, "it would, of course, be foolish to expect models with spurious equations to forecast successfully". In order to see whether the Taylor rule has some property that makes it a good forecasting equation despite the above shown shortcomings, its out-ofsample forecasting ability is next investigated. Should the rule on the other hand be unable to produce good forecasts as well, must the evidence against it as a reasonable description of monetary policy be considered even stronger and its empirical usefulness be judged as minor. 
The out-of-sample forecast exercise will be conducted only for the U.S. since the Australian and Swedish samples are both fairly short. ${ }^{17}$ The out-of-sample forecasts are calculated as follows: initially, equation (5) is estimated on U.S. data from 1979:3 to 1989:4 and these coefficients - together with the actual data on inflation and output gap - are used to generate forecasts up to 1993:4. The sample is then extended one period and new forecasts up to the four year horizon are calculated and so forth. This set-up is obviously very generous in the information given to the Taylor rule, since actual values of the right hand side variables are used as input. Not only is this better than rational expectations - it is actually perfect foresight. Table 5 reports the results from this exercise, where the evaluation of the performance is based on the one quarter to four years forecast horizons. As a comparison, naive forecasts - which are optimal for a univariate unit root process - of the interest rate are also evaluated. The evaluation measures reported in Table 5 are mean error (ME), mean absolute error (MAE) and root mean square error (RMSE) and Theil's $\mathrm{U}^{18}$. Theil's U provides a comparison between a forecast model and a naive forecast; if the model is doing better than the naive forecast, Theil's $\mathrm{U}$ will be smaller than unity.

As can be seen from Table 5, the naive forecast performs better than the Taylor rule on all forecast horizons according to the ME. It is, however, obvious that this is due to systematic over-prediction from the Taylor rule model. The MAE - which probably is a more interesting measure than the $\mathrm{ME}$ - is also lower for the Taylor rule when the forecast horizon is eleven quarters or more. The RMSE and Theil's U further confirms the impression that the Taylor rule model is performing worse than a naive forecast up to a two or three years horizon, but better on the longer horizons.

\footnotetext{
${ }^{17}$ In order to get a reasonable number of forecasts to make comparisons with another model, extremely few observations would be left for estimation and, hence, it does not seem like a relevant exercise to perform for these countries.

18 Theil's $U$ for an $i$-step ahead forecast is calculated as $\sqrt{\frac{\sum\left(\frac{z_{t+i}-\hat{z}_{t+i}}{z_{t}}\right)^{2}}{\sum\left(\frac{z_{t+i}-z_{t}}{z_{t}}\right)^{2}}}$, where $\hat{z}_{t+i}$ is the forecasted value and $z_{t+i}$ the actual.
} 
Table 5. Out-of-sample forecasts for the U.S..

\begin{tabular}{|c|c|c|c|c|c|c|c|}
\hline & $\begin{array}{l}\text { Forecast } \\
\text { horizon in } \\
\text { quarters } \\
(i)\end{array}$ & $\begin{array}{l}\text { Obser- } \\
\text { vations } \\
(T)\end{array}$ & $\mathrm{ME}$ & MAE & RMSE & Theil's U & Sign test \\
\hline \multirow{16}{*}{ Taylor rule } & 1 & 40 & 1.519 & 1.729 & 2.314 & 4.764 & 1.000 \\
\hline & 2 & 39 & 1.591 & 1.815 & 2.413 & 3.326 & 0.998 \\
\hline & 3 & 38 & 1.672 & 1.959 & 2.513 & 2.469 & 0.993 \\
\hline & 4 & 37 & 1.730 & 1.976 & 2.604 & 1.911 & 0.976 \\
\hline & 5 & 36 & 1.752 & 2.005 & 2.666 & 1.556 & 0.986 \\
\hline & 6 & 35 & 1.749 & 2.004 & 2.695 & 1.329 & 0.980 \\
\hline & 7 & 34 & 1.738 & 1.995 & 2.710 & 1.166 & 0.804 \\
\hline & 8 & 33 & 1.737 & 1.996 & 2.736 & 1.059 & 0.500 \\
\hline & 9 & 32 & 1.731 & 1.989 & 2.749 & 0.988 & 0.298 \\
\hline & 10 & 31 & 1.703 & 1.960 & 2.727 & 0.930 & 0.237 \\
\hline & 11 & 30 & 1.664 & 1.918 & 2.682 & 0.875 & 0.292 \\
\hline & 12 & 29 & 1.605 & 1.856 & 2.596 & 0.839 & 0.068 \\
\hline & 13 & 28 & 1.539 & 1.784 & 2.492 & 0.800 & 0.006 \\
\hline & 14 & 27 & 1.459 & 1.694 & 2.352 & 0.767 & 0.003 \\
\hline & 15 & 26 & 1.372 & 1.595 & 2.185 & 0.735 & 0.005 \\
\hline & 16 & 25 & 1.285 & 1.489 & 2.008 & 0.698 & 0.007 \\
\hline \multirow{16}{*}{ Naive forecast } & 1 & 40 & -0.083 & 0.284 & 0.413 & & \\
\hline & 2 & 39 & -0.166 & 0.539 & 0.755 & & \\
\hline & 3 & 38 & -0.262 & 0.804 & 1.066 & & \\
\hline & 4 & 37 & -0.362 & 1.047 & 1.371 & & \\
\hline & 5 & 36 & -0.452 & 1.269 & 1.662 & & \\
\hline & 6 & 35 & -0.490 & 1.447 & 1.904 & & \\
\hline & 7 & 34 & -0.515 & 1.605 & 2.115 & & \\
\hline & 8 & 33 & -0.535 & 1.736 & 2.308 & & \\
\hline & 9 & 32 & -0.530 & 1.839 & 2.456 & & \\
\hline & 10 & 31 & -0.498 & 1.929 & 2.551 & & \\
\hline & 11 & 30 & -0.457 & 1.996 & 2.618 & & \\
\hline & 12 & 29 & -0.403 & 2.042 & 2.641 & & \\
\hline & 13 & 28 & -0.337 & 2.058 & 2.629 & & \\
\hline & 14 & 27 & -0.265 & 2.045 & 2.591 & & \\
\hline & 15 & 26 & -0.189 & 2.011 & 2.520 & & \\
\hline & 16 & 25 & -0.105 & 1.944 & 2.419 & & \\
\hline
\end{tabular}

The evaluation measures presented in Table 5 are point estimates and therefore a formal test proposed by Diebold and Mariano (1995) between competing forecasting models is reported in the far right column. The test is a sign test based on the $i$ horizon absolute forecast error difference $\left(d_{t}^{i}\right)$ between two competing forecasting models. The test statistic, $S^{i}$ is given by $S^{i}=\sum_{t=1}^{T} I_{t}^{i}\left(d_{t}^{i}\right)$

where

$d_{t}^{i}=\left|e_{\text {naive }, t}^{i}\right|-\left|e_{\text {Taylor }, t}^{i}\right|$ 
and

$\left|e_{\text {naive }, t}^{i}\right|$ and $\left|e_{\text {Taylor }, t}^{i}\right|$ are the absolute forecasting errors of the naive forecast and the Taylor rule model respectively at $t$ for horizon $h$ and

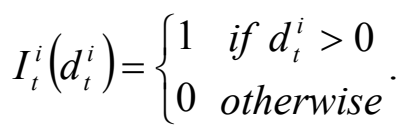

Under the assumption that the loss differential series is iid, the test statistic follows the binomial distribution with parameters $T$ and 0.5 . The results are given as $p$-values from the test where a low $p$-value indicates a better result for the Taylor rule model. It is clear from Table 5 that the Taylor rule model does not perform significantly better compared to the naive forecasts on the forecast horizons shorter than three years. For the longer horizons on the other hand, the Taylor rule significantly outperforms the naive forecast. It should be kept in mind though, that the Taylor rule model has been provided with actual values of the right hand side variables in the forecasting equation. Considering this, it must be considered a huge shortcoming not being able to significantly outperform naive forecasts unless the horizon is at least three years. Judging from the results in the out-of-sample forecast, major support in favour of the Taylor rule has certainly not been added; the model seems to have problems describing the data both within and out-of-sample.

\section{Conclusions}

When Taylor (1993) provided a very simple characterisation of the Federal Reserve's monetary policy, an important contribution to the field of monetary economics was made and it has inspired much empirical and theoretical literature since. The econometric work has, however, not been satisfactory in much of the empirical work and this paper makes a renewed investigation of the empirical relevance of the Taylor rule. The results imply that the Taylor rule is a less appropriate description of central banks' behaviour than has previously been the general opinion. Compatibility is found between the rule and U.S. data from 1960:1 to 1979:2, but in the rest of the investigated samples there is very little support of cointegration between the included variables. This is a major shortcoming of the model since cointegration is a necessary condition for the relevance of the Taylor rule given the I(1) or near integrated behaviour of the variables found in this study. This finding, together with the poor forecasting 
performance of the model, provides evidence that the rule is misspecified. Such misspecification might be one reason for the common finding in many papers that central banks seem to smooth the interest rate (for instance Clarida et al, 1998, 2000); introducing a serially correlated error term through misspecification is extremely likely to generate a significant parameter estimate on the lagged interest rate. This gives further support to the claim of Rudebusch (2002a) and Söderlind et al (2003) that there is something wrong with the Taylor rule.

It is a general conclusion in this paper that data are not very compatible with the Taylor rule. This means that the central banks are doing something else than mechanically following this simple instrument rule. However, it also means that the Taylor rule is not even a close enough approximation to central bank behaviour to be judged as empirically relevant. It can also be noticed that support for the Taylor rule is especially hard to find in the inflation targeting small open economies in this study. Having established serious shortcomings of this formulation of the Taylor rule, it would in the future be interesting to see whether the use of forward looking versions of the Taylor rule and/or real time data makes the model consistent with data.

Considering Romer's (2000) recommendation that the standard aggregate supply and demand framework should be modified to incorporate an interest rate rule, it might still be the case that the Taylor rule can provide a useful simplification. However, estimating Taylor rules on actual data, great care should be taken before statements about central bank policy are made since it is likely that the estimated parameters are inconsistent. 


\section{References}

Akaike, H. (1974), "A New Look at the Statistical Model Identification", IEEE Transactions on Automatic Control 19, 716-723.

Bernanke, B. S. and Mihov, I. (1997), “What Does the Bundesbank Target?”, European Economic Review 41, 1025-1053.

Cheung, Y. and Lai, K. S. (1993), "Finite-Sample Sizes of Johansen's Likelihood Ratio Tests for Cointegration", Oxford Bulletin of Economics and Statistics 55, 313-328.

Clarida, R., Gali, J. and Gertler, M. (1998), "Monetary Policy Rules in Practice. Some International Evidence", European Economic Review 42, 1033-1067.

Clarida, R., Gali, J. and Gertler, M. (2000), "Monetary Policy Rules and Macroeconomic Stability: Evidence and Some Theory”, Quarterly Journal of Economics 115, 147-180.

Crowder, W. and Hoffman, D. (1996), “The Long-Run Relationship between Nominal Interest Rates and Inflation: The Fisher Equation Revisited", Journal of Money, Credit and Banking 28, 102-118.

Culver, S. E. and Papell, D. H. (1997): "Is There a Unit Root in the Inflation Rate? Evidence from Sequential Break and Panel Data Models", Journal of Applied Econometrics 12, 435 444.

DeBoef, S. and Granato, J. (1997), "Near-Integrated Data and the Analysis of Political Relationships", American Journal of Political Science 41, 619-640.

Diebold, F. X. and Mariano, R. S. (1995), "Comparing Predictive Accuracy", Journal of Business and Economic Statistics 13, 253-263.

Doménech, R., Ledo, M. and Taguas, D. (2002), "Some New Results on Interest Rate Rules in EMU and in the US", Journal of Economics and Business 54, 431-446.

Engle, R. F. and Granger, C. W. J. (1987), "Co-Integration and Error Correction: Representation, Estimation, and Testing”, Econometrica 55, 251-276.

Federal Reserve Board. (1995), Federal Open Market Committee Transcripts, Federal Open Market Committee Meeting January 31-February 1, 1995. www.federalreserve.gov/fomc/transcripts

Gerlach, S. and Schnabel, G. (2000), "The Taylor Rule and Interest Rates in the EMU Area", Economics Letters 67, 165-171.

Goodfriend, M. (1991), "Interest Rates and the Conduct of Monetary Policy", CarnegieRochester Conference Series on Public Policy 34, 7-30.

Granger, C. W. J. and Newbold, P. (1974), "Spurious Regressions in Econometrics", Journal of Econometrics 2, 111-120. 
Granger, C. W. J. and Newbold, P. (1986), Forecasting Economic Time Series. Second Edition. Acadmic Press Inc., San Diego.

Hetzel, R. L. (2000), “The Taylor Rule: Is It a Useful Guide to Understanding Monetary Policy?", Federal Reserve Bank of Richmond Economic Quarterly 86, 1-33.

Huang, A., Margaritis, D. and Mayes, D. (2001), "Monetary Policy Rules in Practice: Evidence from New Zealand”, Multinational Finance Journal 5, 175-200.

Johansen, S. (1988), "Statistical Analysis of Cointegration Vectors", Journal of Economic Dynamics and Control 12, 231-254.

Johansen, S. (1991), "Estimation and Hypothesis Testing of Cointegration Vectors in Gaussian Vector Autoregressive Models", Econometrica 59, 1551-1580.

Johansen, S. (1995), Likelihood-Based Inference in Cointegrated Vector Autoregressive Models. Oxford University Press, New York.

Kwiatkowski, D., Phillips, P. C. B., Schmidt, P. and Shin, Y. (1992), "Testing the Null Hypothesis of Stationarity Against the Alternative of a Unit Root: How Sure are We That Economic Time Series Have a Unit Root?", Journal of Econometrics 54, 159-178.

Leitemo, K. and Söderström, U. (2001), "Simple Monetary Policy Rules and Exchange Rate Uncertainty", Working Paper No. 122, Sveriges Riksbank.

Levin, A., Wieland, V. and Williams, J. C. (2001), "The Performance of Forecast-Based Monetary Policy Rules under Model Uncertainty”, Working Paper, Federal Reserve Board.

McCallum, B. T. and Nelson, E. (1999), "Nominal Income Targeting in an Open-Economy Optimizing Model”, Journal of Monetary Economics 43, 553-578.

Minford, P., Perugini, F. and Srinivasan, N. (2002), "Are Interest Rate Regressions Evidence for a Taylor Rule?”, Economics Letters 76, 145-150.

Mishkin, F. (1992), "Is the Fisher Effect for Real?”, Journal of Monetary Economics 30, 195215.

Newey, W. K. and West, K. D. (1987), “A Simple Positive Semi-Definite, Heteroscedasticity and Autocorrelation Consistent Covariance Matrix”, Econometrica 55, 703-708.

Newey, W. K. and West, K. D. (1994),"Automatic Lag Selection in Covariance Matrix Estimation," Review of Economic Studies 61, 631-654.

Nyberg, D. (2002), "Should Exchange Rates be Ignored in the Setting of Monetary Policy?", Working Paper 2002:8, Department of Economics, Stockholm University.

Orphanides, A. (2001), "Monetary Policy Rules Based on Real-Time Data", American Economic Review 91, 964-985.

Pantula, S. G. (1991), "Asymptotic Distributions of Unit-Root Tests when the Process is Nearly Stationary”, Journal of Business and Economics Statistics 9, 63-71. 
Phillips, P. C. B. (1986), "Understanding Spurious Regressions in Econometrics", Journal of Econometrics 33, 311-340.

Phillips, P. C. B. (1988), "Regression Theory for Near-Integrated Time Series", Econometrica $56,1021-1043$.

Reinsel, G. C. and Ahn, S. K. (1988), "Asymptotic Properties of the Likelihood Ratio Test for Cointegration in the Nonstationary Vector AR Model", Technical Report, Department of Statistics, University of Wisconsin-Madison.

Romer, D. (2000), "Keynesian Macroeconomics without the LM Curve", Journal of Economic Perspectives 14, 149-169.

Rudebusch, G. D. (2002a), "Term Structure Evidence on Interest Rate Smoothing and Monetary Policy Inertia”, Journal of Monetary Economics 49, 1161-1187.

Rudebusch, G. D. (2002b), “Assessing Nominal Income Rules for Monetary Policy with Model and Data Uncertainty”, Economic Journal 112, 402-432.

Said, S. E. and Dickey, D. A. (1984), "Testing for Unit Roots in Autoregressive Moving Average Models of Unknown Order”, Biometrika 71, 599-607.

Schwert, G. W. (1989), “Tests for Unit Roots: A Monte Carlo Investigation”, Journal of Business and Economics Statistics 7, 147-159.

Shin, Y. (1994), "A Residual Based Test of the Null of Cointegration Against the Alternative of No Cointegration”, Econometric Theory 10, 91-115.

Svensson, L. E. O. (1999), "Inflation Targeting as a Monetary Policy Rule", Journal of Monetary Economics 43, 607-654.

Svensson, L. E. O. (2002), "What is Wrong with Taylor Rules? Using Judgment in Monetary Policy through Targeting Rules", Forthcoming in Journal of Economic Literature.

Söderlind, P., Söderström, U. and Vredin, A. (2003), "Taylor Rules and the Predictability of Interest Rates", Working Paper No. 147, Sveriges Riksbank.

Taylor, J. B. (1993), "Discretion versus Policy Rules in Practice”, Carnegie-Rochester Conference Series on Public Policy 39, 195-214.

Taylor, J. B. (1999a) "The Robustness and Efficiency of Monetary Policy Rules as Guidelines for Interest Rate Setting by the European Central Bank," Journal of Monetary Economics $43,655-679$.

Taylor, J. B. (1999b), “A Historical Analysis of Monetary Policy Rules”. In: Taylor, J. B. (ed), Monetary Policy Rules. Chicago University Press, Chicago. 


\section{Appendix 1 - Cointegration tests}

A brief description of the different cointegration tests used is given below, where we will first look at the AEG test. The first step in the test involves running a static OLS regression of the form in equation (A1).

$y_{t}=a+\boldsymbol{\beta}^{\prime} \mathbf{x}_{t}+v_{t}$

The residuals from this regression are then tested for the presence of a unit root, using an ADF test, as shown in (A2).

$\Delta \hat{v}_{t}=\rho \hat{v}_{t-1}+\sum_{i=1}^{f} \gamma_{i} \Delta \hat{v}_{t-i}+\omega_{t}$

If the $t$-statistic on $\rho$, which follows a non-standard distribution, is small enough, the null hypothesis of a unit root is rejected, and we conclude that we have found a cointegrating relationship.

In the KPSS test, the initial stage is equivalent to the first stage in the AEG test, i.e. regression (A1) is run. The residuals from this regression are then tested for stationarity using the test statistic in (A3).

$K P S S=T^{-2} \sum_{t=1}^{T} S_{t} / \hat{\sigma}^{2}$

where

$S_{t}=\sum_{j=1}^{t} \hat{v}_{j}$

and $\hat{\sigma}^{2}$ is a consistent estimator of the long-run variance of $v_{t}$. If the test statistic is larger than the critical value, we reject the null of stationarity. Finally, we will consider the two tests based on the methodology developed by Johansen (1988). Consider a VAR of order $p$, as given by equation (A4). 
$\mathbf{y}_{t}=\boldsymbol{\mu}+\mathbf{A}_{1} \mathbf{y}_{t-1}+\cdots+\mathbf{A}_{p} \mathbf{y}_{t-p}+\boldsymbol{\varepsilon}_{t}$

where $\mathbf{y}_{t}$ is a $n \times 1$ vector of non-stationary I(1) variables and $\boldsymbol{\varepsilon}_{t}$ is a $n \times 1$ vector of innovations. We can rewrite the VAR as

$\Delta \mathbf{y}_{t}=\boldsymbol{\mu}+\boldsymbol{\Pi} \mathbf{y}_{t-1}+\sum_{i=1}^{p-1} \boldsymbol{\Gamma}_{i} \Delta \mathbf{y}_{t-i}+\boldsymbol{\varepsilon}_{t}$

where

$\boldsymbol{\Pi}=\sum_{i=1}^{p} \mathbf{A}_{i}-\mathbf{I}$ and $\boldsymbol{\Gamma}_{i}=-\sum_{j=i+1}^{p} \mathbf{A}_{j}$

If the coefficient matrix $\boldsymbol{\Pi}$ has reduced rank $r<n$, then there exist $n \times x$ matrices $\boldsymbol{\alpha}$ and $\boldsymbol{\beta}$ each with rank $r$ such that $\boldsymbol{\Pi}=\boldsymbol{\alpha} \boldsymbol{\beta}^{\prime}$ and $\boldsymbol{\beta}^{\prime} \mathbf{y}_{t}$ is stationary. $r$ is the number of cointegrating relations, the elements of $\boldsymbol{\alpha}$ are known as the adjustment parameters in the vector error correction model and each column of $\boldsymbol{\beta}$ is a cointegrating vector. If $\boldsymbol{\Pi}$ has full rank all variables are stationary. In order to allow for an intercept in the cointegrating relationship but no drift in the system, the constant term is restricted according to $\boldsymbol{\alpha}_{\perp}^{\prime} \boldsymbol{\mu}=\mathbf{0}$. It can be shown that, for given $r$, the maximum likelihood estimator of $\boldsymbol{\beta}$ defines the combination of $\mathbf{y}_{t-1}$ that yields the $r$ largest canonical correlations of $\Delta \mathbf{y}_{t}$ with $\mathbf{y}_{t-1}$ after correcting for lagged differences and deterministic variables when present. ${ }^{19}$ Johansen proposes two different likelihood ratio tests to test the significance of these canonical correlations and thereby the reduced rank of the $\boldsymbol{\Pi}$ matrix: the trace test and maximum eigenvalue test, which are given by equations (A6) and (A7).

$$
\begin{aligned}
& J_{\text {trace }}=-T \sum_{i=r+1}^{n} \ln \left(1-\hat{\lambda}_{i}\right) \\
& J_{\max }=-T \ln \left(1-\hat{\lambda}_{r+1}\right)
\end{aligned}
$$

\footnotetext{
${ }^{19}$ For a detailed description of the procedure, see for instance Johansen (1995).
} 
where $\hat{\lambda}_{i}$ is the $i$ :th largest canonical correlation. The trace statistic, $J_{\text {trace }}$, tests the null hypothesis of the number of cointegrating vectors being less than or equal to $r$ against the alternative hypothesis of $r+1$ or more. The maximum eigenvalue statistic, $J_{\max }$, tests the null hypothesis of the number of cointegrating vectors being less than or equal to $r$ against the alternative hypothesis of $r+1$. If the test statistic is large enough we reject the null for the alternative.

\section{Appendix 2 - Monte Carlo simulations}

It is well established that AR processes with roots close to, but less than, unity behave like unit root processes in "small" samples, but like stationary processes in "large" samples. Since the methodology in this paper partly relies on unit root approximation to near integrated series, it is therefore relevant to investigate for which combinations of sample size and persistence this approximation is appropriate. To clarify the problems we face, consider a system generated according to (A8).

$\mathbf{y}_{t}=\mathbf{B y}_{t-1}+\boldsymbol{\varepsilon}_{t}$

where $\mathbf{y}_{t}$ is a $3 \times 1$ vector and $\boldsymbol{\varepsilon}_{t} \sim N I D\left(\mathbf{0}, \mathbf{I}_{3}\right)$. The persistence of the variables are determined by the matrix $\mathbf{B}=b \mathbf{I}_{3}$.

It is obvious that the regression (A9)

$y_{1 t}=\kappa+\gamma_{1} y_{2 t}+\gamma_{2} y_{3 t}+\lambda_{t}$

is a nonsense regression since the variables are completely unrelated. For I(1) or near integrated variables we therefore want the AEG or Johansen tests to conclude that there is cointegration between these variables with the probability of the chosen size. However, when $b$ is small enough all variables will behave like stationary; this means that the AEG test should conclude that there is cointegration - despite the complete absence of relationship between the variables - since the residual truly is stationary. Moreover should the Johansen tests find three cointegrating vectors in the system. This is a question of test power, but we want to avoid this 
situation since it will not allow us to make statements about the relationship between the variables in the model.

In the Monte Carlo experiment, data are generated according to the system in equation (3) with $b=\left(\begin{array}{llll}1.00 & 0.99 & 0.95 & 0.90\end{array}\right) . T$ is set to $T=\left(\begin{array}{lll}40 & 80 & 160\end{array}\right)$, which largely corresponds to the sample sizes in the empirical part of the paper. The Matlab programming language is used for simulations and the routine RANDN generates pseudo-normal innovations; for each combination of parameters 20000 replications are performed. Setting $b=1$ the system is used to generate finite sample critical values for the three sample sizes for the AEG test and the two Johansen tests by applying (A1), (A2) and (A5). As pointed out in Appendix 1, the constant term in (A5) is restricted according to $\boldsymbol{\alpha}_{\perp}^{\prime} \boldsymbol{\mu}=\mathbf{0}$ to make the VAR consistent with theoretical restrictions. For $b=\left(\begin{array}{lll}0.99 & 0.95 & 0.90\end{array}\right)$ rejection frequencies of the null hypothesis of no cointegrating vector in the system are then computed and are reported in Table A1. These frequencies should be compared to the nominal size of five percent used and in those systems where the cointegration tests have a rejection frequency close to nominal size, we conclude that the approximation is legitimate.

Table A1. Rejection frequencies of cointegration tests applied to system of near integrated variables. Nominal size $5 \%$.

\begin{tabular}{lllll}
\hline$T$ & $b$ & $J_{\text {trace }}$ & $J_{\max }$ & AEG \\
\hline 40 & 0.99 & 0.040 & 0.047 & 0.054 \\
& 0.95 & 0.033 & 0.043 & 0.057 \\
& 0.90 & 0.039 & 0.044 & 0.068 \\
& & & & \\
80 & 0.99 & 0.040 & 0.045 & 0.050 \\
& 0.95 & 0.045 & 0.049 & 0.064 \\
& 0.90 & 0.119 & 0.072 & 0.107 \\
160 & 0.99 & 0.034 & 0.043 & 0.053 \\
& 0.95 & 0.129 & 0.073 & 0.114 \\
& 0.90 & 0.652 & 0.241 & 0.342 \\
\hline
\end{tabular}

Number of simulations: 20000

It can be seen that for $T=40$, all tests have rejection frequencies very close to nominal size for $b$ as low as 0.9 . Increasing the sample size to 80 the probability of rejecting the null hypothesis is still negligibly different from five percent for $b=\left(\begin{array}{ll}0.99 & 0.95\end{array}\right)$, but found to be approximately double the nominal size for $b=0.9$. The performance of the tests when $T=160$ indicates that the unit root approximation is good as long as $b=0.99$; for $b=0.95$ 
the rejection frequency is just above ten percent for both the trace test and the AEG test and for $b=0.9$ all three tests show large departures from nominal size.

The results from the unit root tests presented in Tables 1 and 2 tell us that the variables in the Taylor rule are highly persistent in most samples. But in order to compare the results from the Monte Carlo study above to our data, it is interesting to know how persistent. $\operatorname{AR}(p)$ models on each series were therefore estimated and Table A2 presents the sum of the AR parameters from these regressions.

Table A2. Sum of AR-parameters from estimated univariate AR(p) models.

\begin{tabular}{|c|c|c|c|c|}
\hline & $\begin{array}{c}\text { U.S. } \\
\text { 1960:1-1999:4 }\end{array}$ & $\begin{array}{c}\text { US } \\
1960: 1-1979: 2\end{array}$ & $\begin{array}{c}\text { US } \\
1979: 3-1999: 4\end{array}$ & $\begin{array}{c}\text { US } \\
1987: 4-1999: 4\end{array}$ \\
\hline$i_{t}$ & $\begin{array}{l}0.943 \\
(3)\end{array}$ & $\begin{array}{l}0.904 \\
(4)\end{array}$ & $\begin{array}{l}0.942 \\
(1)\end{array}$ & $\begin{array}{l}0.942 \\
(2)\end{array}$ \\
\hline$\pi_{t}$ & $\begin{array}{l}0.975 \\
(9)\end{array}$ & $\begin{array}{l}0.977 \\
(2)\end{array}$ & $\begin{array}{l}0.912 \\
(5)\end{array}$ & $\begin{array}{l}0.928 \\
(5)\end{array}$ \\
\hline$y_{t}$ & $\begin{array}{l}0.934 \\
(2)\end{array}$ & $\begin{array}{l}0.912 \\
(2)\end{array}$ & $\begin{array}{l}0.938 \\
(2)\end{array}$ & $\begin{array}{l}0.996 \\
(1)\end{array}$ \\
\hline & $\begin{array}{c}\text { Australia } \\
\text { 1993:1-2001:4 }\end{array}$ & $\begin{array}{c}\text { Sweden } \\
\text { 1992:4-2002:4 }\end{array}$ & & \\
\hline$i_{t}$ & $\begin{array}{l}0.855 \\
(2)\end{array}$ & $\begin{array}{l}0.949 \\
(2)\end{array}$ & & \\
\hline$\pi_{t}$ & $\begin{array}{l}0.852 \\
(1)\end{array}$ & $\begin{array}{l}0.829 \\
(1)\end{array}$ & & \\
\hline$y_{t}$ & $\begin{array}{l}0.918 \\
(1)\end{array}$ & $\begin{array}{l}0.910 \\
(2)\end{array}$ & & \\
\hline
\end{tabular}

Lag length, , in parentheses().

The persistence of the different series is very high in general. However, given sample size the sums of the AR coefficients are occasionally not particularly close to one. Highest probability of the null hypothesis of no cointegration being rejected, despite the Taylor rule not being the true relationship between the variables, is likely for the full sample for the U.S.; the rejection frequency for this sample size given the persistence of approximately 0.95 is likely to be twice the nominal size. The persistence in the Australian series also appears to be low, but a simulation with $T=40$ and $b=0.85$ (not reported, but available upon request) shows negligible deviations in rejection frequency from the nominal size of five percent. Comparing Table A1 and A2, it is clear that in most cases the unit root approximation is appropriate for the data considered in this paper. 